\title{
Exportación de conocimiento: Colombia como proveedor de seguridad para la lucha contra el terrorismo y el crimen internacional $^{1}$
}

\section{Export Of Knowledge: Colombia As Security Provider For Fighting Terrorism And International Crime}

César Augusto Niño González²

Fecha de Recepción: 8 de abril de 2016

Fecha de Aprobación: 21 de junio de 2016

\section{Resumen}

El presente artículo pretende arrojar una serie de perspectivas relevantes en materia de seguridad contra el terrorismo y el crimen internacional desde la experiencia colombiana. Este trabajo articula dimensiones estratégicas de manera general, pero se enfoca en las relaciones con África, especialmente con el Cuerno de África. Este documento es una visión panorámica sobre una de las dimensiones en las que Colombia es exportador de conocimiento. En ese orden de ideas, se presentan líneas generales pero estratégicas en la materia, en especial en la lucha contra la piratería.

Palabras clave: Terrorismo, exportación de conocimiento, seguridad, crimen organizado, África.

1 Este artículo es producto del proyecto de investigación institucional titulado: "Seguridad y Paz en escenarios transformados" del Grupo de Estudios en Gobierno y Relaciones Internacionales de la Universidad Santo Tomás.

2 Director del Centro de Investigación y profesor titular de la Facultad de Gobierno y Relaciones Internacionales de la Universidad Santo Tomás. PhD en Derecho Internacional de la Universidad Alfonso X el Sabio, Magister en Seguridad y Defensa Nacionales de la Escuela Superior de Guerra, politólogo e internacionalista de la Universidad Sergio Arboleda. Correo Electrónico: cesarnino@usantotomas.edu.co 


\begin{abstract}
This paper aims to shed a number of relevant perspectives on security against terrorism and international crime from the Colombian experience. This work articulates strategic dimensions in general but focuses on relations with Africa, especially in the Horn of Africa. This document is an overview of one of the dimensions in which Colombia is exporting knowledge. In that vein, but general strategic lines are presented in the matter, especially in the fight against piracy.
\end{abstract}

Keywords: Terrorism export of knowledge, security, organized crime, Africa.

\title{
1. INTRODUCCIÓN
}

El terrorismo internacional se ha convertido en un asunto de gran interés no solo para las grandes potencias, sino también, para la seguridad internacional, involucrando a la gran mayoría de actores en el sistema. Este fenómeno, no es una filosofía ni movimiento, es un método (Wilkinson, 2007) que se configura como procedimiento en la generación de terror con fines políticos antes, durante y después de los actos.

Partiendo de la configuración del terrorismo como amenaza a la seguridad internacional y teniendo en cuenta que la multiplicidad de conceptos contempla una incertidumbre en el intento de denominar al terrorismo en materia jurídica y de acciones defensivas, la experiencia de algunos actores como Colombia en materia contraterrorista es un insumo fundamental para la proyección estratégica del país y para la exportación de modelos de seguridad en escenarios extracontinentales.

La lucha contemporánea contra el terrorismo se ha convertido en un asunto de importancia estratégica en la política internacional. El flagelo del terrorismo no distingue capacidades ni voluntades de los actores con sus respuestas a la amenaza.

En ese sentido, aprovechando las ventajas comparativas que ostenta el Estado colombiano en materia de seguridad y defensa por la guerra irregular y asimétrica dadas las condiciones internas, Bogotá se ha convertido en un punto de referencia en el hemisferio y fuente de conocimiento para otros Estados en el combate contra el 
terrorismo y otras amenazas como el crimen organizado. Si bien el terrorismo y el crimen organizado aún presentan problemas teóricos y epistemológicos sobre su configuración y conceptualización, Colombia presenta una ventaja partiendo del escenario que desde la convencionalidad enfrenta con instrumentos oficiales de manera sistemática las amenazas no convencionales e irregulares. Su agenda de seguridad incorpora las dinámicas relevantes a estos fenómenos, lo cual hace del país un actor que continuamente formula y reformula desde dimensiones estratégicas hasta operacionales para mitigarlos.

Asuntos como el desminado, las interdicciones aéreas, marítimas, eventos estratégicos frente a la capacidad de maniobra militar en terrenos complejos, así como las operaciones conjuntas y combinadas hacen del país un actor relevante en la materia. En ese orden de ideas, desde Colombia se ha planteado la posibilidad en un eventual posconflicto o escenario interno transformado de exportar a gran escala el conocimiento adquirido en estrategia contraterrorista a actores que padecen la amenaza y así despachar los modelos de lucha de Colombia. La importancia de este nuevo escenario para el país radica en el desarrollo de otras herramientas en la búsqueda por la proyección estratégica, el punto focal de referencia y las nuevas dinámicas concernientes a la seguridad internacional.

Desde las Fuerzas Militares y con la preocupación de exportar seguridad se creó la Escuela de Misiones Internacionales y Acción Integral -ESMAI-. No obstante esta institución no es nueva y su creación se remonta a 1991 gracias a las dinámicas que en principio se sustentaban en operaciones de mantenimiento de paz. Esta escuela de formación tiene como objetivo general consolidar su posición como el primer claustro de formación de especialistas en operaciones psicológicas de Latinoamérica. Esto se ha venido ampliando teniendo en cuenta que la seguridad se extrapola de nociones netamente bélicas y trascienden a planos psicológicos, comunicacionales, estratégicos, de conocimiento y demás.

Uno de los escenarios y espacios receptores de la exportación de conocimiento colombiano en materia de seguridad es África. La intención de este manuscrito es entender cómo ha sido la presencia colombiana en algunos espacios africanos para luchar contra el terrorismo y el crimen organizado, especialmente en materia de piratería. África es desde el inicio de la década de los años 90 un escenario particular- 
mente significativo del terrorismo yihadista, aunque sea en estos momentos cuando adquiera una especial relevancia (Reinares, 2011) por el convulsionado espectro de la seguridad en el continente, la variedad de actores irregulares, la expansión y control territorial de facciones terroristas. África se ha convertido en un importante cliente para Colombia, en el cual logra converger un gran portafolio de instrumentos en la lucha contra el terrorismo y demás amenazas al continente.

\section{Puentes con África: Transferencia EN SEguridad}

A partir de 2001, las unidades de operaciones especiales de distintas fuerzas del mundo han desempeńado un papel cada vez más relevante en la lucha contra el terrorismo y el crimen organizado transnacional. La naturaleza irregular de estas amenazas, las dinámicas contemporáneas incluyendo la aversión de la opinión pública a las intervenciones militares a gran escala convierten a estas unidades en instrumentos viables para combatir el terrorismo y el crimen organizado (Del Amo, 2015).

En ese sentido, la asimetría e irregularidad de estas han despertado la necesidad de adoptar medidas efectivas que comprometan menos costos de transacción en los ámbitos económico, político, humano y militar. Dichas medidas se configuran como estrategias de apoyo, control y vigilancia en aras de resolver de manera quirúrgica asuntos que comprometan la seguridad.

"Tradicionalmente, desde su creación en la Segunda Guerra Mundial, las unidades de operaciones especiales han desempeńado, en la gran mayoría de los casos, un papel de apoyo a las fuerzas militares convencionales. Este apoyo consistía, principalmente, en acciones de reconocimiento y sabotaje y en el entrenamiento de efectivos locales con el fin de actuar como multiplicador de fuerza. Sin embargo, durante la última década, estas unidades han ido adquiriendo una importancia cada vez mayor en la lucha contra grupos terroristas, sobre todo en África y Asia. Esto no quiere decir que hayan dejado de actuar como apoyo a las fuerzas convencionales, pero es indiscutible que, actualmente, las unidades de operaciones especiales cuentan con una mayor independencia y un mayor protagonismo que en el pasado" (Del Amo, 2015). 
Si bien Colombia ha estado alejada de las preocupaciones mundiales (Niño, 2015), ha empezado a construir puentes con regiones extracontinentales en materia de seguridad y defensa. África, un continente poco analizado y explorado por los sectores productivos y académicos en el país ${ }^{3}$, configura un escenario atractivo para las proyecciones de Bogotá.

Dentro de los lineamientos del programa -Estrategia de Cooperación Internacional en Seguridad Integral de Colombia-, África comparte una posición especial junto a Centro América y el Caribe en la asignación de prioridades relevantes a la seguridad y la defensa.

En ese orden de ideas, el Gobierno de Colombia diseñó una matriz referente a las áreas temáticas para la cooperación. En ella los ejes sustanciales y sus componentes son los siguientes:

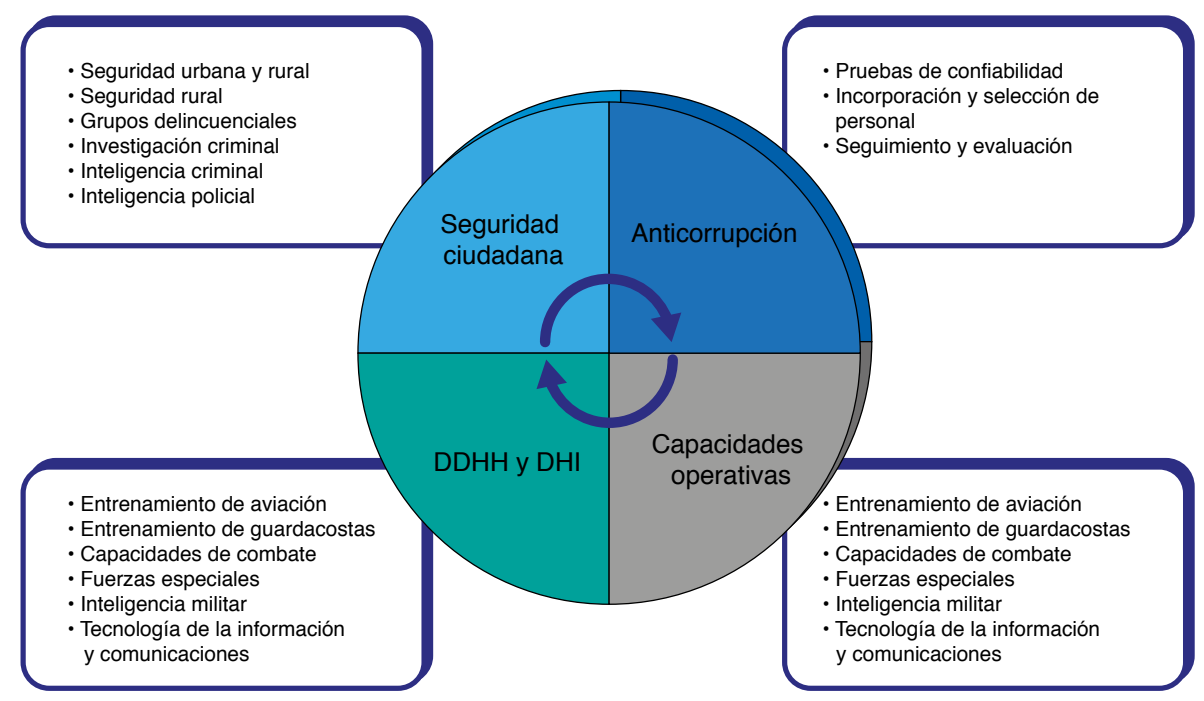

Fuente: (Ministerio de Relaciones Exteriores, 2012). Elaboración propia.

3 El sector industrial, empresarial, bancario y, de alguna manera, los estudios de área del país han excluido de sus portafolios y enfoques de análisis los temas relevantes con África. Si bien se han empezado a tejer canales de comunicación y relaciones bilaterales con África bajo la cooperación sur-sur, aún no existe un plan estratégico de cooperación profunda con dicho continente. Hasta el momento se han trabajado asuntos concernientes al cambio climático, los cuales han arrojado resultados preliminares sobre talleres hechos en Cali con la participación de los gobiernos de Kenia, Senegal y Ghana (Agencia Presidencial de Cooperación Internacional de Colombia, 2014). 
En efecto, cada componente tiene un diseño metodológico referente al diagnóstico de necesidades concretas del país solicitante. Es decir, se ha propuesto un conjunto de instrumentos en un portafolio de servicios. En ese sentido, para lograr la asistencia estratégica, se llevan a cabo actividades académicas para aterrizar la dimensión de un plan de trabajo concreto (Ministerio de Relaciones Exteriores, 2012).

Colombia ha empezado a tender puentes estratégicos con África. El asunto de la seguridad es el centro de gravedad de estos lazos. En enero de 2015, gracias a la redefinición estratégica de las Fuerzas Militares de Colombia, se presentó un convenio marco entre el Estado colombiano y Naciones Unidas para que desde Bogotá se envíen recursos humanos, logísticos y estratégicos en las misiones de paz de la organización (El Tiempo, 2015). Lo anterior conjuga misiones especiales que en las cuales las Fuerzas colombianas han empezado a participar de manera activa.

En primer lugar, las misiones colombianas en esta zona tienen que ver con el Cuerno de África. Allí, la Armada colombiana -ARC- participa como actor clave y estratégico en la operación multinacional Atalanta-2015 bajo el mandato de la Fuerza Naval de la Unión Europea -EUNAVFOR-. En dicha operación, la unidad colombiana interviene de manera directa la embarcación OPV-80 ARC "7 de Agosto" con actividades en las costas de Somalia, la península Arábiga y las Islas Seychelles. Las maniobras de seguridad de la ARC han contribuido a la captura de más de 1.500 piratas y 90 embarcaciones utilizadas para actividades criminales (Saumeth E. , 2015). Este evento proporciona niveles estratégicos en cuanto a la voluntad operacional en conflictos asimétricos e irregulares de Colombia.

\subsection{Operación Atalanta: marco estratégico en la exportación colombiana}

La Operación Atalanta se puso en marcha el 8 de diciembre de 2008. Esta multimisión militar se apoya en la resolución 1816 del Consejo de Seguridad de la ONU, aprobada en junio de 2008 (Real Instituto Elcano, 2011). Acá se despliega un marco estratégico como misión de la operación en la protección del Programa Mundial de Alimentos -PMA-, la salvaguarda de la misión de la ONU en Somalia -AMISOM-, la disuasión, prevención y represión de los actos de piratería y robo a mano armada entre la Península Arábiga y las Seychelles (Real Instituto Elcano, 2011). 
Las condiciones internacionales, en especial las concernientes a la convulsa realidad africana, son escenarios plausibles para la puesta en marcha de las experiencias colombianas en materia asimétrica. La Operación Atalanta, que configura una acción multilateral en materia contraterrorista y anticriminal, necesita de insumos estratégicos, tácticos y operacionales para mitigar amenazas no convencionales. En ese orden, las Fuerzas Militares colombianas han planteado escenarios de combate dentro de Atalanta en situaciones de enfrentamiento en tierra o portuaria. Para dicho efecto, el diseño de la experiencia de las Agrupación de Fuerzas Especiales Antiterroristas Urbanas -AFEUR- (Ejército Nacional de Colombia, 2014) ha servido como referente de acciones conjuntas y coordinadas para el combate frontal, la neutralización y prevención de actos terroristas en zonas geográficas altamente concurrida por civiles y no combatientes.

Colombia es el primer país latinoamericano en enviar una embarcación de guerra a Somalia (Villarejo, 2015). En efecto, la participación colombiana tiene que ver con la diplomacia preventiva ${ }^{4}$ para el establecimiento, la consolidación, la imposición y el mantenimiento de la paz y, en ese sentido, sea cual sea la dimensión, se requiere de una fuerza militar multinacional para preservar o restaurar la paz (Schöndorf, 2005).

Tabla1. Relevantes participaciones de las Fuerzas colombianas en el exterior

\begin{tabular}{lllcr}
\multicolumn{1}{c}{ Misión } & Fuerza & \multicolumn{1}{c}{$\begin{array}{c}\text { Unidad } \\
\text { operacional }\end{array}$} & $\begin{array}{c}\text { Número de } \\
\text { efectivos }\end{array}$ & Año \\
\hline Guerra de Corea & $\begin{array}{c}\text { Ejército- } \\
\text { Armada }\end{array}$ & $\begin{array}{l}\text { Batallón Colombia } \\
\text { No.1 }\end{array}$ & 4.102 & $1951-1954$ \\
\hline $\begin{array}{l}\text { UNEF- Misión de Paz en el } \\
\text { Canal de Suez }\end{array}$ & Ejército & $\begin{array}{l}\text { Batallón Colombia } \\
\text { No.2 }\end{array}$ & 2.115 & 1956
\end{tabular}

4 Según Naciones Unidas, cuando una crisis estalla o amenaza con detonar la violencia, la acción diplomática pronta (también conocida como diplomática preventiva) es uno de los utensilios disponibles más antiguos de las Naciones Unidas para evitar que se agrave la situación. Hoy en día, este instrumento ha tomado fuerza en la ONU a medida que los logros pacíficos alimentan la confianza en su aplicación, las últimas inversiones en capacidad se asientan, las posibilidades de las asociaciones efectivas se expanden y los Estados Miembros buscan respuestas a las crisis en un momento de tensión económica a nivel mundial (Organización de las Naciones Unidas, 2012). 


\begin{tabular}{|c|c|c|c|c|}
\hline Misión & Fuerza & $\begin{array}{c}\text { Unidad } \\
\text { operacional }\end{array}$ & $\begin{array}{l}\text { Número de } \\
\text { efectivos }\end{array}$ & Año \\
\hline $\begin{array}{l}\text { Misión de Paz del MFO- } \\
\text { Península del Sinaí- }\end{array}$ & Ejército & $\begin{array}{l}\text { Batallón Colombia } \\
\text { No.3 }\end{array}$ & 500 & $\begin{array}{c}1982- \\
\text { actualmente }\end{array}$ \\
\hline $\begin{array}{l}\text { Misión de Paz en } \\
\text { Yugoslavia-UNPROFOR- }\end{array}$ & Policía & $\begin{array}{l}\text { Policía Nacional e } \\
\text { Inteligencia policial }\end{array}$ & 30 & $1992-1995$ \\
\hline $\begin{array}{l}\text { Misión de Paz en Camboya } \\
\text {-UNTAC- }\end{array}$ & Policía & $\begin{array}{l}\text { Segundo } \\
\text { Contingente }\end{array}$ & 50 & 1992-1993 \\
\hline $\begin{array}{l}\text { Misión de Paz en El } \\
\text { Salvador-ONUSAL- }\end{array}$ & Policía & Policía Nacional & 33 & 1994 \\
\hline $\begin{array}{l}\text { Misión de Paz en Guatemala } \\
\text { - MINIGUA- }\end{array}$ & Policía & Policía Nacional & 34 & 1994 \\
\hline $\begin{array}{l}\text { Misión de Paz y de } \\
\text { estabilización en Haití } \\
\text { - MINUSTHA- }\end{array}$ & Policía & $\begin{array}{l}\text { Policía Nacional, } \\
\text { antisecuestro, } \\
\text { antinarcóticos, } \\
\text { antiexplosivos }\end{array}$ & 34 & 2006 \\
\hline
\end{tabular}

Fuente: (Conferencia de Ejércitos Americanos, 2014), (Ejército Nacional, 2014), (Escuela de Misiones Internacionales y Acción Integral, 2015), (Policía Nacional, 2012). Elaboración propia.

En ese sentido, es relevante hacer hincapié en que la información anterior es muestra de escenarios de participación de operadores de seguridad colombianos en procesos de estabilización. No obstante, los nuevos teatros de participación de las fuerzas están diseñados para la mitigación de amenazas.

Retomando las dimensiones estratégicas de la Operación Atalanta y la participación colombiana para combatir las amenazas en el Cuerno de África, las lógicas de la asistencia de Bogotá tienen que ver con la interoperabilidad, las comunicaciones, manejo de crisis en terreno y despliegue rápido de las fuerzas. Las interdicciones marítimas y terrestres frente a la piratería y demás manifestaciones de criminalidad son los puntos clave en los que se desenvuelven los estrategas colombianos en territorio afri- 
cano. Es relevante mencionar que los resultados de la operación militar Atalanta han sido evidentes pasando de los 163 ataques de 2009 a los 2 de 2014 (Villarejo, 2015).

\section{Multicriminalidad: amenaza común y compartida entre Colombia y Somalia}

África es punto de convergencia en dinámicas subterráneas. Allí se encuentran variables que suscitan amenazas a la seguridad regional que van desde regímenes autoritarios, corrupción, violaciones a los derechos humanos, tráfico de armas, drogas y recursos naturales, la trata de personas, hasta manifestaciones de grupos terroristas y piratería.

En los últimos años han aumentado significativamente los ataques piratas, en particular en el Golfo de Adén, Somalia y el Océano Índico. Este tipo de sucesos afecta a amplias zonas marítimas, por lo que resulta difícil prevenirlos (Interpol, 2014).

Específicamente, tanto Colombia como Somalia, presentan un conjunto de amenazas comunes que han ido presentando procesos de securitización hasta el punto de concebirlas compartidas. En ese sentido, la securitización se entiende como la dinámica en la cual los Estados logran trascender los fenómenos de un espectro político o económico ordinarios hasta incorporarlos en la parte sustantiva de la consideración de las cuestiones en asuntos de amenaza (Albert \& Buzan, 2011). Mogadiscio y Bogotá, a pesar de la distancia geográfica, presentan particularidades comunes en cuanto a la presentación de amenazas y compartidas referente a la incorporación de ellas en las agendas de seguridad.

Teniendo en cuenta lo anterior, las nuevas dinámicas de la seguridad entre estos actores llevan a precisar que las amenazas y problemas a su seguridad vienen de causas diversas y asimétricas (Ayoob, 1998). No obstante, a pesar de compartir los fenómenos, Somalia presenta una alta vulnerabilidad por razones estructurales y coyunturales, lo que genera una incapacidad en las respuestas. 
Tabla 2. Panorama sobre la piratería en Somalia ${ }^{5}$

\begin{tabular}{|lc|}
\hline \multicolumn{1}{c}{ Factores } & Datos \\
\hline Operaciones piratas & $4.000 .000 \mathrm{~km} 2^{1}$ \\
\hline Pérdidas económicas & $315-385$ millones de dólares en pérdidas \\
\hline Buques rescatados & 149 \\
\hline Muertes registradas & 100 \\
\hline Secuestros por parte de piratas & 3.741 personas de 125 nacionalidades \\
\hline Tiempo promedio de personas en estado de secuestro & 3 años \\
\hline Pérdidas comerciales marítimas para Somalia & $7,4 \%$ anual \\
\hline Pérdidas al comercio mundial & 18 mil millones de dólares al año \\
\hline Pagos por rescate de personas y mercancías & 53 millones de dólares al año \\
\hline Afectación a las importaciones y exportaciones & $25 \%$ \\
\hline Afectación de la industria del atún & $26,8 \%$ \\
\hline $\begin{array}{l}\text { Ganancias repartidas entre políticos y líderes } \\
\text { corruptos de la región }\end{array}$ & $70-86 \%$ \\
\hline Barcos pesqueros cautivos & 44 \\
\hline
\end{tabular}

Fuente: (Banco Mundial, 2013). Elaboración propia

La piratería es tan solo un componente de la multicriminalidad en Somalia y las áreas estratégicas aledañas. Sin embargo, la piratería logra fungir y acaparar otras modalidades criminales que afectan la seguridad nacional somalí y la regional a gran escala.

Los piratas utilizan embarcaciones de pequeño tamaño, rápidas y maniobrables para perseguir a sus víctimas o escapar de las autoridades. Si antes amenazaban a los tripulantes con espadas y cañones, hoy su armamento comprende desde primitivas armas blancas, cortas y ligeras hasta sofisticadas armas antitanque y avanzados instrumentos electrónicos para localizar a sus eventuales perseguidores (Sobrino, 2014).

5 Por primera vez, la piratería en Somalia fue denunciada en el ańo 2005.

6 Los piratas somalíes operan más allá de Somalia. Sus actividades registran acciones criminales en el Océano Índico, el Mar Rojo y el Golfo de Adén (Banco Mundial, 2013). 
En la dinámica colombiana, los grupos criminales y los carteles del narcotráfico hacen uso de sofisticados equipos militares a bordo de sus embarcaciones o vehículos para custodiar las mercancías ilícitas, proteger las rutas y corredores de narcotráfico o para movilizarse de manera rápida por los canales fluviales y marítimos del país.

Los carteles del narcotráfico en Colombia han logrado construir y adquirir submarinos para llegar con total autonomía a las costas de los países centroamericanos con principal destino las costas de México y de Estados Unidos (BBC, 2011). Es decir, las lanchas rápidas y las avionetas ya no son los instrumentos más sofisticados para los criminales, se valen de la alta tecnología para evadir a los operadores de seguridad.

No obstante, el trabajo estratégico y operativo entre las distintas fuerzas de seguridad del país ha hecho de la labor conjunta y coordinada una plataforma plausible en las operaciones de interdicción marítima y aérea para neutralizar, capturar y abatir a los criminales. Este tipo de ejercicios han sido las herramientas que desde la convencionalidad han dado óptimos resultados sobre las amenazas irregulares. Las interdicciones e interceptaciones son los modelos de seguridad que mejor se adaptan a la exportación en África, especialmente en Somalia.

\subsection{Entre la interdicción e interceptación: claves de exportación colombiana}

La Fuerza Aérea Colombiana ha venido desarrollando ciertos tipos de escenarios para el entrenamiento y proyección estratégica tanto en la región como en escenarios extracontinentales.

La Fuerza Aérea Colombiana cuenta con la capacidad, el entrenamiento en operaciones asimétricas referentes a la criminalidad y a las amenazas no convencionales. Dentro de su doctrina de operaciones aéreas, la fuerza concibe dos tipos de ejercicios estratégicos y operacionales para contrarrestarlas. La primera de ellas son las interdicciones.

Las interdicciones son ataques aéreos a las rutas de abastecimiento del enemigo para impedir o limitar que se refuerce (Fuerza Aérea Colombiana, 2014). Este tipo de operaciones busca cortar los canales estratégicos de las comunicaciones y suministros y pueden darse como medida preventiva para evitar avances en las rutas de los criminales por aire y por mar. 
Los registros en materia de interdicciones contra grupos del narcotráfico y redes criminales en las operaciones estratégicas de las fuerzas colombianas arrojan resultados en materia cuantitativa relativamente preocupantes. No obstante, la capacidad de los operadores de seguridad de controlar y desmantelar rutas de tráfico ilícito es incuestionable, la sensación de los resultados estadísticos genera una gran ambigüedad. Por un lado, que se están descubriendo y detectando las acciones ilegales gracias a los recursos tecnológicos y estratégicos de las unidades de combate o, por el otro, que la actividad ilegal se encuentra en crecimiento y proliferación constante.

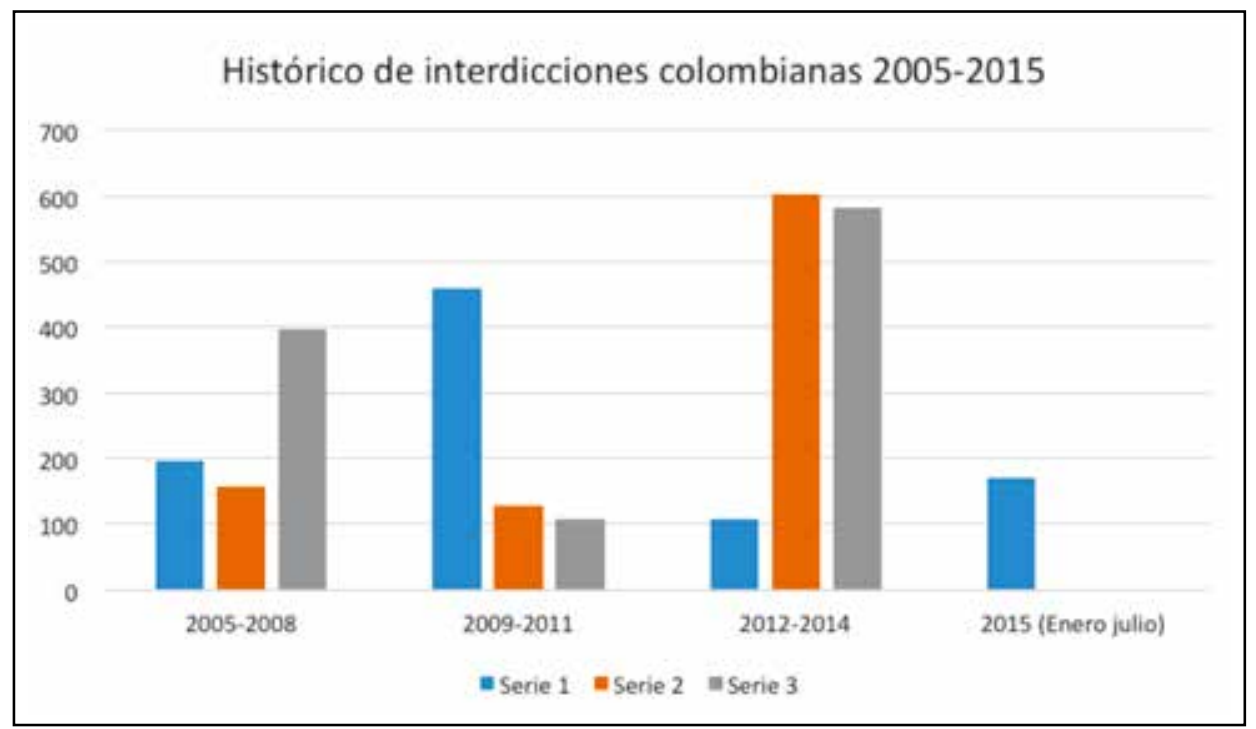

Fuente: (Ministerio de Defensa, 2015). Elaboración Propia

La segunda tiene que ver con las interceptaciones. Estas son procesos para llevar un arma aérea al encuentro de una "traza" (aeronave) clasificada como enemiga o desconocida (Fuerza Aérea Colombiana, 2014). Las interceptaciones son concebidas como parte de las Operaciones Defensivas de Contrapoder Aéreo. La mixtura estratégica entre las interdicciones y las interceptaciones responde a cuestiones concretas en la exportación de conocimiento hacia Somalia y la región. La piratería es un fenómeno irregular y asimétrico, en el cual la experticia colombiana logra acomodarse en la proyección de capacidades y recursos para afrontar la multicriminalidad. En ese 
orden de ideas, las claves en la exportación de seguridad de Colombia a África, especialmente a Somalia, radican en la interoperabilidad y capacitación del trabajo conjunto y coordinado entre las fuerzas. Esos asuntos son vitales en el portafolio de servicios. $^{\text {. }}$

\subsection{Operaciones combinadas y conjuntas: acciones estratégicas}

La Operación Atalanta responde a las dinámicas de operaciones combinadas. Este tipo de operaciones son acciones militares en las cuales convergen y participan fuerzas de distintos Estados bajo un Comando y Estado Mayor Combinado (Santos \& Pardo, 2010). Dichas operaciones se llevan a cabo en situaciones de prevención de conflictos, desarrollo de crisis e imposición de orden en teatros de guerra y de operaciones convulsos.

Las operaciones combinadas han sido instrumentos de participación de las fuerzas colombianas en misiones especiales, en las cuales el papel fundamental ha sido la aportación en cuestiones estratégicas en conflictos asimétricos. Por ejemplo, en operaciones de interdicción e interceptación, en 2014 tuvieron lugar ejercicios militares con Panamá y Estados Unidos en la incautación de 1.524 kilos de cocaína en la isla del Tigre en la comarca de Guna Yala en Panamá (Fuerza Aérea Colombiana, 2014).

Este tipo de maniobras militares, a pesar de estar bajo un mando combinado, permite la puesta en marcha de planes y procedimientos de experticia de los actores involucrados en áreas temáticas. Colombia, dentro de Atalanta, es un actor clave y fundamental en cuanto a la lucha contra la piratería marítima y terrestre se refiere.

En el hemisferio, la puesta en marcha de ejercicios combinados se configura en la necesidad de desarrollar capacidades en el teatro de operaciones. En efecto, Colombia ha participado constantemente desde su creación en la Operación Unitas7 que consiste en un ejercicio naval combinado. En 2013, Colombia fungió como anfitrión y convocó la participación de más de 14 Estados. Esa ocasión fue el primer ejercicio en

7 Unitas es un ejercicio naval promovido por los Estados Unidos que surgen a partir de la Primera Conferencia Naval sostenida en Panamá en 1959 y realizada bajo el Tratado Interamericano de Asistencia Recíproca (TIAR). Colombia y Estados Unidos son los dos únicos países que han participado de forma ininterrumpida en sus 54 versiones (El Universal, 2013). Unitas es la Operación multinacional más antigua del mundo (Partnership of the America, 2015). 
que se emplearon fragatas y submarinos colombianos después de la modernización de los equipos militares de la ARC en el Plan Orión (Saumeth E. , 2013). En efecto, Colombia ha venido estando presente, a su medida, en circunstancias cruciales concernientes a la seguridad internacional. Por tal razón, las prácticas llevadas a cabo en las operaciones combinadas sirven para medir capacidades estratégicas y de operatividad en dinámicas irregulares.

No obstante, referente a la Operación Atalanta, esta fuerza multinacional es un escenario preciso para la interoperabilidad de fuerzas. A saber, con Atalanta, los operadores de seguridad de Colombia fungen dinámicas de maniobra con operaciones conjuntas dentro de la combinación de las mismas (Santos \& Pardo, 2010). Es decir, las conjuntas son aquellas en las cuales las acciones militares se ejecutan por distintas fuerzas como la aérea, la terrestre y la marítima. La multiplicación de las capturas de buques en Somalia ha puesto la piratería en el centro de mira de los medios de información y de los centros de operaciones navales (Del Pozo, 2009). La estrategia de la lucha contra la piratería y los derivados criminales como el terrorismo obligan a repensar los tipos y cursos de acción de las fuerzas convencionales. Por tal razón, la práctica colombiana de trabajo conjunto y combinado demuestra que estas dimensiones deben ser consideradas para trabajar en el terreno african ${ }^{0}$.

Tabla 3. Modelo de exportación de conocimiento colombiano

\begin{tabular}{|lll}
\hline \multicolumn{1}{|c|}{ Conocimiento } & \multicolumn{1}{c}{ Receptor } & \multicolumn{1}{c}{ Durabilidad } \\
\hline Operaciones conjuntas & Operaciones multinacionales & Por misión \\
& Operaciones multinacionales & Por misión \\
Operaciones combinadas & $\begin{array}{l}\text { Estados mayores } \\
\text { Operadores de seguridad nacionales } \\
\text { del actor receptor }\end{array}$ & $\begin{array}{l}\text { Mutuo acuerdo sobre } \\
\text { capacitación }\end{array}$ \\
& Operaciones multinacionales & Mutuo acuerdo sobre \\
Interdicciones & Estados mayores \\
& Cuerpos operativos & capacitación \\
\hline Interceptaciones & Operaciones multinacionales & Mutuo acuerdo sobre \\
& Estados mayores & capacitación
\end{tabular}

Fuente: elaboración propia 


\section{Conclusiones}

El presente documento es una visión panorámica y preliminar de las acciones exteriores en materia de seguridad en el combate contra el terrorismo y el crimen organizado. Ha sido una apuesta por presentar de manera general espacios extracontinentales que se escapan en buena medida a los análisis académicos nacionales en política exterior e incluso a los actores gubernamentales.

Desde la academia y desde los tomadores de decisiones se ha empezado a hacer recomendaciones sobre las nuevas y futuras misiones de los operadores de seguridad colombianos en escenarios transformados. De allí se desprenden un cúmulo de opciones y abanicos para el dinamismo de las mismas, no obstante el avance debe ser progresivo racional frente a capacidades y voluntad del Estado colombiano en la materia.

Colombia ha estado alejada de las preocupaciones mundiales por dinámicas concernientes a su conflicto interno y demás variables. No obstante, la repotenciación y los planes estratégicos de sus fuerzas militares han llevado a un diseño prospectivo en materia de seguridad y defensa. Las Fuerzas Militares y la Policía, bajo las nuevas reorientaciones estratégicas de sus misiones internas y externas, han empezado a construir escenarios plausibles para la proyección de capacidades.

En ese sentido, si bien el país ha abierto un abanico de asociaciones y cooperación en materia de seguridad con países de Centroamérica por la cercanía geográfica, también ha tendido puentes con actores extracontinentales. Entre ellos la participación con operaciones multilaterales de la Unión Europea y la OTAN, en las cuales Colombia desempeńa un papel relativamente estratégico en la asistencia y lucha contra el terrorismo y el narcotráfico.

Esos puentes extracontinentales tendidos bajo el amparo de una fuerza multilateral presentan una oportunidad en la exportación de conocimiento en conflictos irregulares y asimétricos. A saber, el trabajo diseñado para asistir a las fuerzas multinacionales y solventar los problemas y amenazas a la seguridad en África gira en torno a las experiencias y conocimientos del Estado colombiano en la lucha contra fenómenos no convencionales. 
Los puntos clave en exportación de dichos conocimientos son relativos a las operaciones conjuntas, coordinadas y combinadas. Ellas tres son un capital estratégico, en el cual los operadores de seguridad colombianos diseñan y modelan prototipos de escenarios de prevención, combate y mantenimiento de zonas seguras gracias a las interdicciones e interceptaciones.

El papel de Colombia en materia de seguridad internacional está forjándose en cuanto al liderato en lucha asimétrica e irregular. A pesar de las dificultades teóricas sobre la precisión del terrorismo, en el campo estratégico y operacional, Colombia tiene una ventaja considerable por las capacidades e instrumentos que se emplean sistemáticamente desde la convencionalidad para enfrentar la irregularidad.

\section{REFERENCIAS}

Agencia Presidencial de Cooperación Internacional de Colombia (21 de Julio de 2014). Colombia estrecha sus lazos de cooperación con África. Obtenido de https://www.apccolombia.gov.co/?idcategoria $=1730$

Albert, M., \& Buzan, B. (2011). Securitization, sectors and functional differentiation. Security Dialogue, pp. 413-425.

Ayoob, M. (1998). Subaltern realism: international relations theory meets the third world. En S. Neuman, International Relations Theory and the Third World. (pp. 31-54). St. Martin's Press.

Banco Mundial (2013). Banco Mundial. Obtenido de Infografía de la piratería en Somalia: http://www.worldbank.org/content/dam/Worldbank/Feature\%20Story/Africa/Somalia/acabar-con-la-pirateria-en-somalia-infografia.pdf

BBC (19 de Abril de 2011). BBC Mundo. Obtenido de Los submarinos narcos de Colombia: http://www.bbc.com/mundo/noticias/2011/04/110419_galeria_submarinos_nar cos_drogas_colombia_aw.shtml

Conferencia de Ejércitos Americanos. (12 de Mayo de 2014). Ejército Nacional. Obtenido de http://www.ejercito.mil.co/?idcategoria=346599 
Del Amo, F. (2015). Las unidades de operaciones especiales en la lucha contra el terrorismo: el caso de EE.UU., Reino Unido, Francia y España. Madrid: Instituto Español de Estudios Estratégicos.

Del Pozo, F. (2009). Aspectos operacionales de la lucha contra la piratería en Somalia. Madrid: Real Instituto Elcano.

Ejército Nacional de Colombia (2 de Agosto de 2014). Sinai, Misión de Paz. Obtenido de http://www.ejercito.mil.co/?idcategoria=74084

Ejército Nacional de Colombia (12 de Mayo de 2014). Agrupación de Fuerzas Especiales Antiterroristas. Obtenido de http://www.ejercito.mil.co/?idcategoria=84

El Tiempo (27 de Enero de 2015). Las cinco claves del acuerdo firmado entre Colombia y la ONU. El Tiempo, pp. 1-2.

El Universal (9 de Septiembre de 2013). Armada Nacional, anfitriona de la operación Unitas. Obtenido de http://www.eluniversal.com.co/colombia/armada-nacional-an fitriona-de-la-operacion-unitas-134005

Escuela de Misiones Internacionales y Acción Integral. (12 de junio de 2015). Ejército Nacional. Obtenido de http://www.ejercito.mil.co/?idcategoria=321550

Fuerza Aérea Colombiana (9 de Octubre de 2014). Comando Aéreo de Combate No. 4. Obtenido de https://www.cacom4.mil.co/\%C2\%BF-interdicci\%C3\%B3n-o-intercep taci\%C3\%B3n-a\%C3\%A9rea

Fuerza Aérea Colombiana (8 de Marzo de 2014). Fuerza Aérea Colombiana participa en operaciones combinadas logrando capturar una lancha con droga en Panamá. Obtenido de https://www.fac.mil.co/fuerza-a\%C3\%A9rea-colombiana-participa-en-operacionescombinadas-logrando-capturar-una-lancha-con-droga

Interpol (14 de Septiembre de 2014). Piratería marítima. Obtenido de http:// www.interpol.int/es/Criminalidad/Pirater\%C3\%ADa-mar\%C3\%ADtima/ Pirater\%C3\%ADa-mar\%C3\%ADtima

Ministerio de Defensa (12 de Agosto de 2015). Ministerio de Defensa. Obtenido de Logros PISDP: http://www.mindefensa.gov.co/irj/go/km/docs/Mindefensa/Documentos/descargas/estudios\%20sectoriales/info_estadistica/Logros_Sector_Defensa.pdf 
Ministerio de Relaciones Exteriores. (2012). Estrategia Internacional de Cooperación Internacional en Seguridad Integral de Colombia. Bogotá: Ministerio de Relaciones Exteriores.

Niño, C. A. (24 de Marzo de 2015). Grupo de Estudios en Seguridad Internacional. Obtenido de http://www.seguridadinternacional.es/?q=es/content/colombia-y-la-seguridad-internacional-exportaci $\% \mathrm{C} 3 \% \mathrm{~B} 3 \mathrm{n}$-de-conocimiento-contra-el-estado-isl $\% \mathrm{C} 3 \% \mathrm{~A} 1$ mico

Organización de las Naciones Unidas. (Diciembre de 2012). Operaciones de Paz de la ONU. Obtenido de http://www.un.org/es/peacekeeping/publications/yir/2011/diplomacy.shtml

Partnership of the America. (Agosto de 2015). Unitas. Obtenido de https://www1.mar.mil. br/unitasamphib2015/es

Policía Nacional. (Febrero de 2012). Policía Nacional. Obtenido de http://oasportal.policia. gov.co/aniversario122/pdf/Policia_misiones_ONU.pdf

Real Instituto Elcano. (2011). ABC de la misión en Somalia. Madrid: Real Instituto Elcano.

Reinares, F. (2011). Terrorismo yihadista en el Este de África: nexos entre la célula de alQaeda en Kenia y al-Shabab en Somalia. Madrid: Real Instituto Elcano.

Santos, M., \& Pardo, C. (2010). Diccionario político, estratégico y militar. Bogotá: Escuela Superior de Guerra.

Saumeth, E. (3 de Agosto de 2013). La Armada Nacional de Colombia anfitriona en los ejercicios UNITAS Caribe 2013. Obtenido de http://www.infodefensa.com/la$\operatorname{tam} / 2013 / 08 / 03 /$ noticia-la-armada-nacional-de-colombia-anfitriona-de-los-ejerciciosunitas-caribe-2013.html

Saumeth, E. (10 de Marzo de 2015). Infodefensa. Obtenido de Colombia se une a la operación multinacional Atalanta 2015: http:/www.infodefensa.com/latam/2015/03/10/ noticia-armada-comlombiana-operacion-multinacional-atalanta2015.html

Schöndorf, E. (2005). Suggestions on Terminology. Konstanz: Universidad de Konstanz.

Sobrino, J. (2014). Piratería y terrorismo en el mar. La Coruña: Universidad de La Coruña.

Villarejo, E. (12 de Agosto de 2015). ABC. Obtenido de http://abcblogs.abc.es/tierra-maraire/public/post/colombia-pirateria-somali-18865.asp/

Wilkinson, P. (2007). Grupos y redes terroristas. En P. Wilkinson, Una brevísima introducción a las Relaciones Internacionales (p. 103). México: Oceano. 